\title{
The Impact of Overconfidence on Investors' Decisions
}

\author{
Boubaker Adel, Talbi Mariem \\ International Finance Group Tunisia, \\ Faculty of Management and Economic Sciences of Tunis \\ Tunisia, El Manar University, Tunis Cedex, C. P. 2092, Tunisia
}

Received: June 20, 2013 Accepted: July 4, 2013

doi:10.5296/ber.v3i2.4200

URL: http://dx.doi.org/10.5296/ber.v3i2.4200

\begin{abstract}
The purpose of this paper is to study the impact of the bias of overconfidence on the decisions of investors, specifically to evaluate the relationship between the bias, trading volume and volatility. The empirical study on a sample of 27 companies listed on the stock exchange in Tunis, observed over the period, which runs from 2002 until 2010.

The results we have achieved, through the application of tests and VAR modeling ARMA-EGARCH indicate the importance of confidence bias in the analysis of characteristics of the Tunisian financial market.
\end{abstract}

Keywords: Efficiency, Behavioral finance, Overconfidence, Stock returns, Trading volume, Excess volatility, VAR, EGARCH

\section{Introduction}

The theory of efficiency is indeed one of the most controversial theories in economics and finance theories. Despite the amplitude of empirical work to test the hypothesis of efficiency, no obvious conclusion seems to be clear. This absence of unanimous results is certainly related to the importance of efficiency in the financial theory.

The efficiency market hypothesis $(\mathrm{EMH})$ requires the validation of a number of conditions: the rationality of investors, the free flow of information, the market's atomicity and liquidity. The good performance of financial markets is based on the validation of these five conditions, but this one proves not easily applicable, due to some shortcomings related to investor behavior.

According to the literature finding, the investors decisions are not perfectly rational, the EMH is unable to explain certain anomalies detected on the financial market, This was the origin of the emergence of a new research program "behavioral finance", this new current treats at the same time psychology and finances, was able to focus on the behavior of investors in the 
financial market through different psychological biases among these biases, we find through overconfidence as the choice of this bias seems very important in terms of choice of the financial decisions.

The purpose of this paper is to analyze the impact of overconfidence bias on investor decisions, in Tunis stock market through the use of data collected from the stock market of Tunis (Tunis Stock Exchange).

First, we present the theoretical foundations of EMH by evaluating the size of the efficiency of financial market based on the literature review, and its contribution in the field of modern finance, as well as the recently observed anomalies in financial markets. That contributed to devalue this current, which allowed the entry of a new current "behavioral finance", in this context, we recall the notion of overconfidence and its role occupied in the field of behavioral finance, through a range of studies on this concept, while referring to the existing theoretical and empirical literature and various reflections.

Second, we present the data collected from the stock market of Tunis and the methodology.

Finally, we present an empirical validation test which will be on the Tunisian context; we tried to present the main results. The aim of our research is to detect the impact of overconfidence on investors' decisions, based on different statistical tools.

\section{1 Literature Review}

Before presenting the basic assumptions of the EMH, we have tried to present the definition of the efficiency hypothesis as presented by Fama (1965), "an efficient market is a market where all agents are rational whose price should reflect fully and instantly all the published information on the market", so investors will be able to tap instantly and adequately to the occurrence of information for inclusion in the asset price, tell that four conditions.

The investor rationality: its rational expectation, that is to say that investors can maximize the benefit they make for a given level of risk or minimize risk for a given gain level.

The free flow of information: All investors can simultaneously benefit from the same information, in order to act immediately on the market under identical conditions.

The absence of transaction costs and tax: The investor is when the expected benefits outweigh the transaction costs and tax as they can influence investor reaction and end investors and atomicity liquidity.

This efficiency hypothesis was defined according to the first classification of Fama (1965) in three forms: The weak form; where the information contained in past prices of the market is fully reflected in asset prices. Therefore, during the titles reflect their historical, it is not possible to take advantage of the information passed on a financial asset. The semi-strong form; in which it is impossible to predict the future value of a share price based on historical data and data publicly accessible, and the high form or any non-public information are reflected in the course, so it is not possible for an investor to take advantage of inside information, but this definition has been renewed by Fama (1991) and the weak form; 
becomes the test of predictability of returns which aims to analyze the returns rate , highlighting the unpredictability of these rates, the semi-strong form tests becomes event studies with the aim to determine the speed of price adjustment to the announcement of new information.

This efficiency concept is based upon two key assumptions: rationality: this hypothesis rests on the notion of fundamental value that equals the present value of future dividends rationally anticipated by the agents (Allais 1953). It also relies on the notion of homo economics, which is based on the theory of expected utility, as the market is efficient, if asset prices which are quoted is only based on rational expectations, as there are three types of rationality. Procedural rationality or the agent is limited in its ability to collect and pay information (Simon 1978), and instrumental rationality based on the choice of instrument in which the individual adopts a utility maximizing behavior and late cognitive rationality which is stewed for a match between the information received from agents and performances that make them Walliser (1989). One can conclude that anticipation is called rational if it incorporates optimally all available information at the level of financial market, the rationality of agents, consists firstly in that the investor is able to formulate rational expectations and secondly to maximize their expected utility. The second hypothesis embodies the arbitration, it is a financial transaction that includes all positive flow with a non zero probability .This operation is to conduct two simultaneous operations (buying and selling), on two assets with similar characteristics that is to say substitutable at different prices, to end to make a profit with no risk and no initial cash outlay. According to Ross (1976), founder of the first principle of arbitration, this operation is based on the law of unique price, where two identical assets must be negotiated at the same price, we can conclude that a market has an arbitrage opportunity if given prices, it is possible to conduct an investment strategy based on a zero capital income guarantees positive for all states of the world.

This notion of efficiency is still unable to explain certain anomalies detected on the financial market as the anomaly is defined by Rabin and Thaler (2004), as "an empirical result difficult to rationalize or require unrealistic assumptions to be explained".

Among these anomalies, we find the effect later this year or January effect, the effect of firm size, the effect low price-earnings ratio, the weekend effect, the effect of end months, the value effect, the momentum effect, and the phenomenon "data snooping". These anomalies are regarded as evidence of market inefficiency, giving birth to a new trend; it is behavioral finance, which challenges the fundamental assumptions of the theory of efficiency. This new trend is based on two assumptions further that stand out significantly from the assumptions that underlie the EMH.

The first is that some investors are not fully rational and their demand for financial assets at risk is affected by their beliefs or emotions, which obviously are not fully justified by economic "fundamentals".

These investors are called noises traders. The second assumption is that arbitration, an activity which will deliver the second category of investors, who are themselves fully rational activity is not without risk and whose effectiveness is therefore limited. It connects the 
current investor psychology to finance; it combines the results of experiments in cognitive psychology to the concepts and principles of finance in order to decipher the anomalies at the end to explain the irrational behavior of investors in the financial market.

One can conclude, therefore, the role occupied by the behavioral finance that is melted on behavioral psychology and the existence of bias influencing the financial decisions taken, this current is used to explain observed phenomena in the financial market as arbitrage opportunities lasting, over or under-reaction courses, self -correlation of returns. It offers a renewed vision of the issue of agents' behavior in financial markets by psychological biases that are due to faulty reasoning or emotions that can lead investors to act irrationally in these decisions especially in situations of uncertainty.

In this case the two psychologists Kahneman and Tversky (1979), conducted researches on cognition investors it is made in, cognitive biases, feelings and attitudes, their behaviors in total these biases increase when individuals form their beliefs and preferences, were considered errors of decision making, such as a behavior adopted to face a situation resulting from a weakness in the processing of an available information.

So we talk about behavioral biases that constitute a new pattern that complement the traditional theory of finance, such as the presence of these biases is evidence of the emergence of the irrationality that is related to the process of decision making. Among these biases are found optimism bias, the representativeness algorithmic, conservatism or mental affix, found through overconfidence which is based on our research, according to this aim, investors tend to overestimate their private signals, that is to say, to have an exaggerated confidence in their own skills as information is generated by their own thoughts and abilities, among the consequences of this bias is the excessive transaction.

This bias is defined as behavior that the individual ignores errors or failures and therefore, contributes to the creation of the illusion of control over events that led him to overestimate these opportunities and these capabilities.

It always tends to overestimate his ability in different contexts; this bias has been highlighted by all economic and financial studies which aim to provide a convincing explanation of abnormal phenomena occurring in the market.

According to De Bondt and Thaler (1995), they found that: "overconfidence the result is the strongest identified by psychological research that is to say, investors tend to overestimate the probability of accuracy of their information, their successes and capabilities".

According to Shiller (1997)," overconfidence is associated with people in their own judgments, these individuals underestimate the margins of error likely to be committed", Odean (1998), which states that investors treat first information leading to biased choices, they maintain their positions although they do not result in a profit that is to say: losing as to maintain constant their level of confidence.

As to Barber and Odean (2001), they have identified that investor's confidence prove their pride in their beliefs and they ignore any belief from rational investors, it will be a difference 
of opinion and an increase in transaction volume.

Daniel and Al (2002), who showed, from their study that this bias is used to explain certain anomalies, such as the reaction of stock prices.

According to Lovigne and Legros (2005), this bias is considered the source large volumes of transaction; this bias can lead to problems and affects the volume of transaction, such QUELA volatility of assets subject to such transactions and their yields

Stracca (2004), Bénabou and Tirole (2004) who argue that "This bias is the result of self-attribution as describing individuals tend to attribute successes to their own judgments while the failures are due to luck and external factors".

As to Broihanne, Merli and Roger (2004), this bias is considered that the search for information by the private investor and grant him too much.

Chuang and Lee (2006), this bias does play down or weaken the investment risk that is to say, leads agents to underestimate the level of risk of their investments and so on-hold portfolios diversified.

Kumer (2006), which linked through to this uncertainty, whichever is higher, more investors can make mistakes and exhibit increased overconfidence. There are also many new studies that have been shown to measure this behavioral bias includes a title example.

As to Ronald Huisman, Nico L. Van Der Sar, Remco CJ Zwinkels (2012), they suggested a new method for measuring investor confidence in using data to end well determined to make their predictions on the stock market, they applied the estimation of Parkinson's which is based on extremes around the prediction of action for deduct on investor confidence.

As the aim is to examine directly whether some investors are confident about their predictions. This measure is based on the evaluation of Parkinson's volatility (Amsterdam Exchange Index), the results show that some investors display a significant view that confidence on the prediction of equity volatility is less than the implied volatility.

Other economic actors as Gerlinde Fellner, Sebastian Krügel (2011), who proposed a new measure of this bias, which is captured as behavioral models, the reliability of signals, the results and the importance of private information. The latter two have made a distinction between the overestimation of the accuracy Knowledge of own predictability of a time series and the overestimation of the predicted signals from three judgment tasks based on three types of information: forecasts based on information that is not explicitly available , but that external data is in memory, forecasts of a variable based on previous values of this variable and the end of the forecast of a variable explicitly on information available on the value of another variable.

Menkhoffa Lukas, Maik Schmelinga Ulrich Schmidtb, c, (2013), in their study, presented a line-experience on overconfidence in the context of market funding. As the sample consists of institutional investors, investment advisors and individual investors.

Each of them being registered users a great platform online data on market sentiment. 
Because of their record, several socio-economic characteristics of participants can be ordered in their analysis. It turns out that there are stable differences in overconfidence among the three groups of investors.

In addition, the investment experience has a significant impact on the degree of excess of confidence that will surprisingly in reverse. Where these results have important implications for the studies on the impact of the experience on the behavior of markets (financial).

According Dimitris Andriosopoulos has Kostas Andriosopoulos b Hafiz Hoque (2013), a repurchase shares on the open market is not a commitment, and there is little evidence on whether firms repurchase shares under. They showed that disclosure information and overconfident CEOs are important determinants of the rate of completion of redemption shares. In addition, they found that large companies that perform buyback programs for further action, and have a reputation of completion, have higher completion rates.

Finally, they assessed whether other features of CEOs affect the completion of redemption rates and find that companies with executives who hold external mandates can have a mandate over as CEO are more likely to complete the repurchase programs. In sum, the results suggest that there is a clear relationship between information disclosure, CEO overconfidence and the completion of redemption rates.

Sanjay Deshmukh, Anand M. Goel b, Keith M. Howe (2013) developed a model of the dynamic interaction between CEO overconfidence and dividend policy.

They found that the dividend level is about one sixth in low managed by leaders who are more likely to be overconfident businesses. They attested that the reduction in dividends associated with CEO overconfidence is greater in company's opportunities for growth lower and lower cash flows.

They also showed that the magnitude of a positive market reaction to the announcement of increased dividends is higher for firms with greater uncertainty about CEO are confident.

To analyze the overconfidence hypothesis, we presented the relationships between the bias and information (private-public).

According to Chuang and Lee (2006), the two types of information can generate volumes of transaction and security prices under-react to the shock of public information and then reach the equilibrium response. The transaction is generated by informed investors actively sharing their private information.

The second linkage is the overconfidence and trading volume, as according to Statman, and Thorly Vorkink (2004), this link is plausible because trading volumes are positively correlated with over the months proceeding, such as increasing courses during a period, causes an increase in the confidence of investors who are tempted to negotiate advantage of the next period.

The third and last relation is defined as the ratio between the bias and volatility as according Chaung and Lee (2006), the excessive trading in action on investor confidence contributes to 
excessive volatility. They concluded that the high level of market volatility is due to the presence of excess investors and asymmetric effect of positive and negative signals on asset returns, while showing that negative innovations on returns assets tend to increase volatility more than positive.

\section{Data and Methodology}

\subsection{Data}

In terms of market capitalization, the Tunis stock market is considered to be close to the small number of companies listed on them. As can be noted that it is dominated by companies in the financial sector.

In our empirical study, we investigated the impact of this bias on investments decisions, which aims to propose an empirical full implications study of the various hypothesis of overconfidence by focusing on the overall behavior of investors. We had recourse to a representative sample of the financial market consisting of 27 shares (AMEN BANK, ATB, ATL, BH, BIAT , BNA, BT, CIL, ELECTROSTAR, GENERAL STORE, SFBT, SIAME, SIMPAR, SIPHAT, SOTETEL, SOTRAPIL, SOTUVER, STAR STB STEQ, CST LEASING, UBCI, UIB, AIR LIQUIDE CST, ALKIMIA, GSI, CST LAI), The choice of the number of companies is due to the data availability, this brings us back to consider all Tunisian shares from 1 January 2002 to 31 December2010.

The actions in our sample must have information on stock prices, trading volume (turnover) and market capitalization. In fact, we use daily data from Tunis Stock Market to build the daily observations inspired by the famous research paper "investor overconfidence and trading volume".

Statman Al, (2004) and Wen-Ichaung, Bong-Soo Lee (2006). We use turnover (turnover rate) as a measure of volume of transactions. In fact the turnover rate may better reflect the reality that direct employment of shares traded, given the variation of the outstanding securities of the firm due, for example, to the capital increase.

\subsection{Methodology}

H1: Investors react over-confident after the shock of private information and under react after the shock of Public Information: People tend to underestimate their disagreement errors by making predictions; they give significant weight to their own forecasts relative to those of other forecasters.

To test this hypothesis, we used the VAR model:

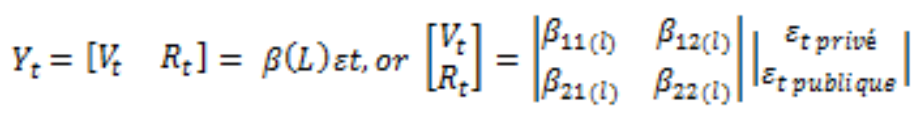

As: the detrended trading volume (measured by turnover), the stock return. $\varepsilon$ t private: the private information shock, public et: the public information shock. : For $i, j=1,2$ is the polynomial operator in L such that: 
$\beta_{i j \mathbb{a}(\mathbb{b})}=\sum k b_{i j}(K) L^{k}$ and $\operatorname{Var}\left(\varepsilon_{\mathrm{t}}\right)$ is an identity matrix of rank 2.

H2: Market gains prompting investors confident about negotiating aggressively in subsequent periods:

This idea was highlighted by several studies, for example, Glaser and Weber (2004). This gave the idea of the causal relationship between the asset returns and trading volume. The vector auto-regression (VAR) is used to study the interaction of turnover and the time series of returns for the end market has to prove that VT returns depend delayed:

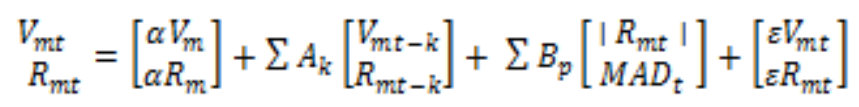

$V_{\text {mat }}$ : The detrended trading volume that measured by turnover or the turnover rate at time.

$R_{m s}$ : The market return at time.

$\left|R_{m: t}\right|$ : The absolute value of broad market return at time $\mathrm{t}$.

$M A D_{t}$ : Denotes the deviation of mean absolute cutting performance that is to say transverse to the standard deviation time $\mathrm{t}$ yields. It is weighted by market value of securities, this variable and the market return, is intended to explain the effect of the volatility time series. To calculate the market return, we used stock market indices:

$$
R_{\mathrm{it}}=R_{\mathrm{mit}}=\frac{\mathrm{ct}-[\mathrm{Ct}-1)}{[\mathrm{Ct}-1)}
$$

Stock prices generally are used on the closing price. For the average deviation of cross-market:

$$
\begin{gathered}
M A D_{t}=\sum_{i=1}^{N} W_{i}\left|R_{\text {itt }}-R_{m t}\right| \\
\text { With: } W_{\mathrm{i}}=\left(\frac{\text { capitalization of shares i }}{\text { market capitalization }}\right)
\end{gathered}
$$

$W_{i}:$ The (value-weighted) weight of stock i.

$R_{\text {it }}$ : The return on stock i, $R_{m t}:$ the market-wide return. 
$\mathrm{N}$ : the total number of all action in the sample.

The trading volume is measured by turnover or the turnover rate is defined as follows:

$$
\text { turnover }=\left(\frac{\text { number of shares traded of the stock i }}{\text { number of shares exchange of the stock i }}\right)=\left(\frac{\text { nit }}{\text { wit }}\right)
$$

H3: the excessive trading of shares on investor confidence contributes to excessive volatility:

The purpose of our third hypothesis is to prove that the transaction in excessive action of confident investors contributes to excessive volatility. We shall, therefore, by the context empirically that we can check whether the excessive volatility comes from the excessive trading on investor confidence.

We begin by dividing the volume of transactions into two components: to model and predict volatility. We applied the EGARCH model, to estimate this model, there are several steps. The first part is to estimate the regression that breaks the VT in two parts, the first part reflects the behavior of investors confident, presented by the delayed returns. The second part captures the influence of other factors, the present model and the constant residual term.

$$
\begin{gathered}
V_{\text {mat }}=\text { turnovermt }=\alpha+\sum_{j=1}^{p} \beta_{j} R_{m i t-j}+\varepsilon_{\mathrm{t}}=\left[\sum_{j=1}^{p} \beta_{j} R_{\text {mat }-j}\right]+\alpha+\varepsilon_{\mathrm{t}} \\
V_{m \mathrm{t}}=\text { Overconfidence }+ \text { not Overconfidence }=\mathrm{E}+\mathrm{NE}
\end{gathered}
$$

$R_{m \mathrm{t}}:$ Variable market return.

$V_{m t}$ : Variable trading volume.

a: Constant

P: Residual term.

$\beta_{j^{*}}$ Optimal number of lags to include in the model, determined by the information criteria.

$\beta_{j}:$ Factors associated with past returns.

The residuals are defined as the component unrelated to over-confident investors and the difference between transaction volume and the sum of constant terms means overconfidence due to past asset returns (ECT).

The idea of decomposing the transaction volume in two parts, back to the fact that it can be affected by several factors other than overconfidence. The number of delay $(\mathrm{P})$ to be included 
will be determined using the criteria of Akaike and Schwartz. The selection procedure of the order of representation is to estimate all models for an order from 0 to $h$ (h being the maximum allowable delay in economic theory or available data).

The number of delay p selected, will be one that minimizes the AIC or SC. We also take into account changes in the value of log-likelihood since a slight improvement of this value shows a further refinement of the model.

Test the effect of trust on the volatility of market returns: Estimated ARMA (p, q): checking the stationary of the time series of returns, we allow the calculation of the conditional mean of this series, for that the calculation requires the stationary of series. We can apply the Box-Jenkins (1976) without estimating the conditional mean. Models ARMA (p, q)-specific calculation of the conditional expectation is of a general $\operatorname{ARMA}(p, q)$.

$$
\left(1-\theta 1 D-\theta 2 D^{2}-\cdots \theta n D n\right) y t=\left(1-\alpha 1 D-\alpha 2 D^{2}-\cdots \alpha q D q\right) \varepsilon t
$$

They are therefore representative of a process generated by a combination of the values of past and past errors. The orders $\mathrm{p}$ and $\mathrm{q}$ of ARMA model are determined from a series of correlogram coefficients of auto-correlations (simple and partial), this by considering the orders corresponding to the auto-correlations significantly different from zero.

After estimating the conditional expectation, it is wise to test the relationship between overconfidence and the conditional volatility. In this case the EGARCH model is the primary means used to model and predict this volatility, this model allows both devices to capture shocks in the estimation of uncertainty and allows the treatment and the distinction of those negative and positive shocks and that of the asymmetry of the reaction yields to the signs of shock.

$$
\begin{aligned}
& R_{m \mathrm{t}}=\mu_{\mathrm{t}}+\tau_{\mathrm{t}} \\
& \tau_{t}\left(V_{m t}, \tau_{t-1}, \tau_{t-2}, \ldots, R_{m t-1}, R_{m t-2}\right) \sim n(0, h t) \\
& \ln h_{\mathrm{t}}=\omega+f 1\left(\frac{\left|\pi_{\mathrm{t}-1}\right|+\mathrm{hi}_{\mathrm{t}-2}}{\sqrt{h_{\mathrm{t}-1}}}\right)+f 2 \ln h_{\mathrm{t}-2}+f 3 E C_{\mathrm{t}}+f 4 N E C_{\mathrm{t}}
\end{aligned}
$$

$\mathrm{K}$ : volatility parameter to capture the leverage effect, if $\mathrm{k}$ significant and negative; the presence of asymmetry.

$\mu_{\mathrm{t}}$ : Average conditional on date $\mathrm{t}$ on the set of past information.

$\tau_{\mathrm{t}}$ : Residues from the equation of the conditional mean at time $\mathrm{t}$.

ht: conditional volatility at time t. 
EC: the exchange part motivated by a feeling of confidence and outcome of this model.

NEC: Part exchange unrelated to past market returns and outcome of this model.

f 1: parameter measuring the recurrence relation between the conditional and the unconditional prior period.

f 2: parameter measuring the recurrence relation between the conditional variance and that of the previous period.

f 3: parameter measuring the effect of overconfidence on the conditional variance.

f 4: parameter measuring the effect of factors other than reliance on the conditional variance.

\section{Results and Interpretations}

Before analyzing the assumptions of this bias, we conducted preliminary tests to know the stationary test as the stationary is a necessary condition in any procedure for estimating a model to prove that this is representative of the studied phenomenon.

We used the Dickey and Fuller (ADF) that allows highlighting the character or not a stationary series and taking into account the autocorrelation of a differentiated set via a correction using the values delayed.

The Phillips Perron test (PP) which takes into account that errors may be heteroscedastic, the second test is the normality test series where the descriptive analysis is based primarily on analysis of two coefficients of flattening Kurtosis and asymmetric Skweness as normal for the law, they are respectively 0 and 3 .

Table1: Structure of descriptive statistic:

Following the analysis table of descriptive statistics, these two coefficients are different from 0 and 3 ; in addition to the Jarque-Berra statistics shows zero probability.

Hence the rejection of null hypothesis of normal distribution of the series. We can conclude that all series of stock returns $\left(R_{i t}\right)$; transaction volumes(Vit) per share which is measured by turnover $\left(T U R N_{i t}\right)$, deviation of the market (MAD) (standard deviation of cross market return), market return $\left(R_{m t}\right)$ and total transaction volume $\left(\left(T U R N_{G}\right)\right.$, do not follow the normal distribution, with respect to the stationary test, all series are stationary, because they have values of $\mathrm{ADF}$ and PP below the critical values shown directly by Eviews to seuils $1 \%, 5 \%$ and $10 \%$.

For the variable $\left(R_{i t}\right)$, we took the rate of stock returns of 27 companies in the form of a single variable according to panel data, to facilitate and improve the empirical results, the same approach to variable turnover $\left(T U R N_{i t}\right)$. It is for this reason, the results of two 
Stationary tests (ADF and PP) give us important values for these two variables $V_{t}$ and $\mathrm{R}_{\mathrm{it}}$ are driven by two types of shocks that are distinguished by an identification restriction imposed on the VAR model, used to capture the asymmetric effect of two types of information about $V_{t}$, that is to say that private $\varepsilon$ an impact on $V_{t}$ while $\varepsilon$ t public has no impact on which is mainly due to the weight accorded by investors confident of their private information and insufficient weight attached by public information. The estimation results of the VAR model, after determining the optimal number of delay, within this framework, we chose the VAR (2), because it minimizes the information criteria and maximizes the log likelihood.

Table1. Descriptive statistics

\begin{tabular}{|l|l|l|l|l|l|}
\hline Variable & $R_{\text {it }}$ & Vit & MAD & $R_{\text {mt }}$ & TURN $_{G}$ \\
\hline Mean & 0.000225 & 0.000740 & 0.006591 & 0.000643 & 0.000489 \\
\hline Maximum & 0.708972 & 0.659308 & 0.124085 & 0.036794 & 0.010646 \\
\hline Minimum & -1.000000 & 0.000000 & 0.000644 & -0.048805 & 1.73 E-0.5 \\
\hline Std.dev & 0.021502 & 0.004703 & 0.004811 & 0.005220 & 0.000646 \\
\hline Skewness & -15.53119 & 69.11747 & 10.69417 & -0.167543 & 6.687332 \\
\hline Kurtosis & 719.4974 & 7834.254 & 208.5473 & 13.31909 & 71.28012 \\
\hline Jarque-bera & $1.28 \mathrm{E}+09$ & $1.53 \mathrm{E}+11$ & 3937957 & 9851.241 & 447394.3 \\
\hline Probability & 0.000000 & 0.000000 & 0.000000 & 0.000000 & 0.000000 \\
\hline Observation & 59882 & 59882 & 2213 & 2213 & 2213 \\
\hline
\end{tabular}

Table 2. Stationary daily series

\begin{tabular}{|c|c|c|c|c|c|c|}
\hline & Rit & Vit & $\mathrm{Rmt}$ & MAD & TURN G & \\
\hline & \multicolumn{5}{|c|}{ calculated value } & critical value \\
\hline $\begin{array}{l}\text { with constant } \\
\text { (ADF) }\end{array}$ & -34.09566 & -23.11026 & -9.357873 & -7.287366 & -5.878762 & $\begin{array}{l}1 \%:-3.430291 \\
5 \%:-2.861398 \\
10 \%:-2.566735\end{array}$ \\
\hline $\begin{array}{l}\text { With constant } \\
\text { and } \\
\text { trend(ADF) }\end{array}$ & -34.09564 & -23.19727 & -9.562849 & -7.337168 & -8.171259 & $\begin{array}{l}\text { 1\%: }-3.958187 \\
5 \%:-3.409877 \\
10 \%:-3.126647\end{array}$ \\
\hline $\begin{array}{l}\text { with constant } \\
\text { (PP) }\end{array}$ & -252.2731 & -302.1727 & -38.10739 & -46.37997 & -47.27678 & $\begin{array}{l}1 \%:-3.430290 \\
5 \%:-2.861398 \\
10 \%:-2.566734\end{array}$ \\
\hline $\begin{array}{l}\text { With constant } \\
\text { and trend } \\
(\mathrm{PP})\end{array}$ & -252.2704 & -301.3025 & -37.99000 & -46.15758 & -44.74405 & $\begin{array}{l}1 \%:-3.958186 \\
5 \%:-3.409877 \\
10 \%:-3.126647\end{array}$ \\
\hline
\end{tabular}

H1: Investors reaction over-confident after the shock of private information and under 
reaction after the shock of Public Information:

Table 3. Criteria for choosing the optimal lag order of VAR model

\begin{tabular}{|l|l|l|l|}
\hline delays & Log-likelihood & AIC & SC \\
\hline 1 & 386030.3 & -12.89412 & -12.89322 \\
\hline 2 & 386591.0 & -12.91866 & -12.91475 \\
\hline 3 & 386273.0 & -12.90455 & -12.90245 \\
\hline 4 & 386584.3 & -12.91611 & -12.91340 \\
\hline 5 & 386588.9 & -12.91743 & -12.91412 \\
\hline 6 & 386193 & -12.9072 & -12.89922 \\
\hline
\end{tabular}

Following results show that $R_{i t}$ has a positive and significantly different from 0 out $V_{t}$ because the $\mathrm{t}$ statistic of $R_{i t}$ student at a late and worth (5.11671) is greater than the critical value which is about 1.96 at $5 \%$, confirming the existence of a positive relationship between two variables $R_{i t}$ and $V_{t}$.

Table 4. Estimation results of the VAR model (2)

\begin{tabular}{|l|l|l|}
\hline & Rate of stock returns & Turnover \\
\hline Rit $(-1)$ & 0.043134 & $\mathbf{0 . 0 0 4 9 3 1}$ \\
& $(0.00409)$ & $\mathbf{( 0 . 0 0 0 9 6 )}$ \\
& {$[10,5410]^{* *}$} & {$[\mathbf{5 . 1 1 6 7 1}]^{* *}$} \\
\hline Rit $(-2)$ & 0.023819 & 0.001360 \\
& $(0.00378)$ & $(0.00089)$ \\
& {$[6.29749]^{* *}$} & {$[1.52643]$} \\
\hline Turnover $(-1)$ & 0.133293 & 0.081175 \\
& $(0.01735)$ & $(0.00408)$ \\
& {$[7.68414]^{* *}$} & {$[19.8717]^{* *}$} \\
\hline Turnover (-2) & 0.126329 & 0.068893 \\
& $(0.01735)$ & $(0.00409)$ \\
& {$[7.28214]^{* *}$} & {$[16.8638]^{* *}$} \\
\hline
\end{tabular}

Confidence level: $1 \%(*) ; 5 \%(* *) ; 10 \%(* * *)$

These results are improved by impultionel response functions; these functions trace the effect of a shock, a standard deviation of an innovation current and future value of endogenous variables.

According to the analysis of pattern of these functions, $R_{i t}$ has a null response during the first period after following a shock to $V_{t}$ and then increases during the second and third 
period and then return to balance during the fourth period by a correction process. Same response to $V_{t}$ after the shock of $R_{i t}$, we can conclude that $V_{t}$ is induced by investors who actively sharing their private information and heterogeneous interpretations of public information on investors to conduct trading volumes, that is to say $R_{i t}$, it has an impact on investor confidence and trading activity on the posterior.
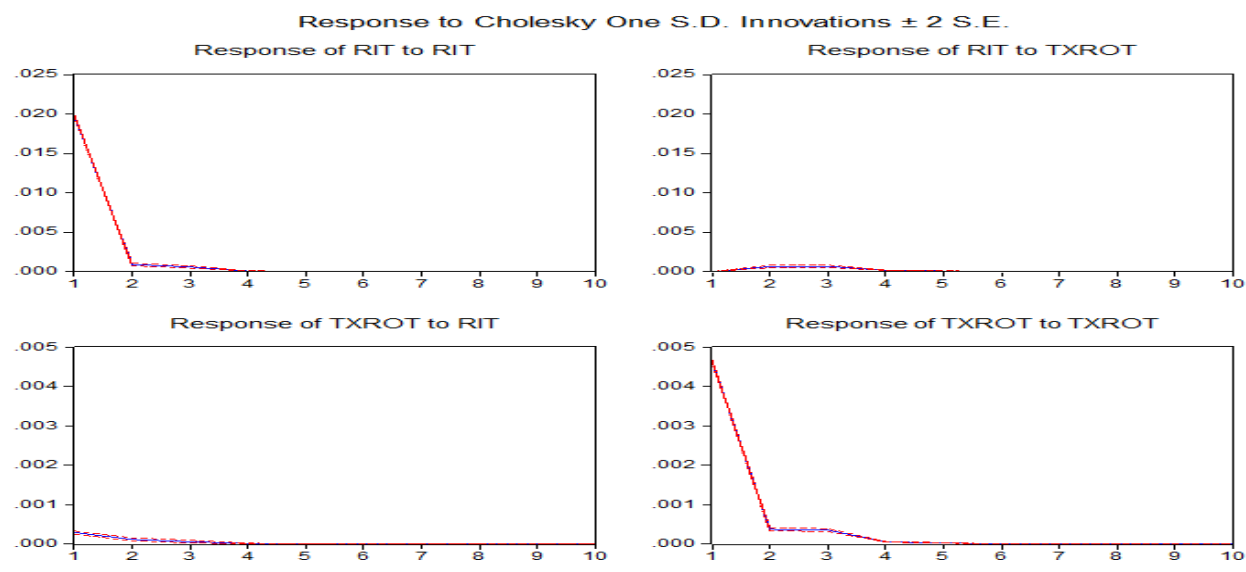

Figure 1. Schematic of impulse response functions

$\mathrm{H} 2$ : market gains prompting investors confident about negotiating aggressively in subsequent periods:

The results of the VAR model, after determining the optimal number of delay in this case is chosen, the VAR model of order 3 that minimizes the information criteria and maximizes the $\log$ likelihood.

Table 5. Criteria for choosing the optimal lag order of VAR model

\begin{tabular}{|l|l|l|l|}
\hline delays & Log-likelihood & AIC & SC \\
\hline 1 & 30434.43 & -27.56903 & -27.53804 \\
\hline 2 & 30385.85 & -27.59187 & -27.53752 \\
\hline 3 & 30465.02 & -27.74146 & -27.65340 \\
\hline 4 & 30402.02 & -27.73122 & -27.64006 \\
\hline
\end{tabular}

Estimation results show that $R_{m t}$ in a positive and significantly different from zero as t-statistic student at a delay of 1 and worth (2.25253) is greater than the critical value which is about 1.96 at $5 \%$ level, $R_{m t}$ where at one level of delay can positively influence the.

Table 6. Estimation results of the VAR model (3)

\begin{tabular}{|l|l|l|}
\hline & Turnover amount & Market efficiency amount \\
\hline$(-1)$ & 0.005528 & 0.190599 \\
& $(0.00245)$ & $(0.02161)$ \\
\hline
\end{tabular}




\begin{tabular}{|l|l|l|}
\hline & {$[2.25253]^{* *}$} & {$[8.81869]^{* *}$} \\
\hline$(-2)$ & 0.002403 & 0.055655 \\
& $(0.00249)$ & $(0.02195)$ \\
& {$[0.96428]$} & {$[2.53544]^{* *}$} \\
\hline$(-3)$ & -0.000956 & -0.022543 \\
& $(0.00245)$ & $(0.02161)$ \\
& {$[-0.38974]$} & {$[-1.04327]$} \\
\hline TURN $(-1)$ & 0.162365 & 0.312264 \\
& $(0.02001)$ & $(0.17624)$ \\
& {$[8.11327]^{* *}$} & {$[1.77180]$} \\
\hline TURN (-2) & 0.089578 & 0.264244 \\
& $(0.02016)$ & $(0.17753)$ \\
& {$[4.44362]^{* *}$} & {$[1.48844]$} \\
\hline TURN (-3) & 0.102762 & 0.398886 \\
& $(0.02068)$ & $(0.18208)$ \\
& {$[4.97027]^{* *}$} & {$[2.19071]^{* *}$} \\
\hline
\end{tabular}

Confidence level: $1 \%(*) ; 5 \%(* *) ; 10 \%(* * *)$

It was applied as the test of Granger causality to test the causal link between the two variables. Similarly the results of causality prove the existence of dual or causal relationship retroactive (feedback) between the two variables for the probability that does not cause $R_{m t}$ is inversely $V_{t}$.is very low hence the second hypothesis is verified.

Table 7. Results of Granger Causality test.

\begin{tabular}{|l|l|l|l|}
\hline Null Hypothesis & Observation & F-Statistic & Prob. \\
\hline Does not Granger Cause & 2213 & 4.42230 & 0.0121 \\
\hline Does not Granger Cause. & & 3.78730 & 0.0228 \\
\hline
\end{tabular}

H3: the excessive trading of shares on investor confidence contributes to excessive volatility:

Following the estimation of regression which breaks down the transaction volume in two parts, we have noticed that all the coefficients are significant in terms of t-statistics in terms of probability; this shows the dependence of $V_{t}, R_{m t}$ of the previous period.

Table8. Decomposition of trading volume

\begin{tabular}{|l|l|l|l|l|}
\hline & coefficient & Std error & t-statistics & Probability \\
\hline C & 0.000483 & 1.38 E-05 & 35.3113 & 0.0000 \\
\hline Rm (-1) & 0.009709 & 0.002623 & 3.701321 & 0.0002 \\
\hline & F-Statistics & 13.69973 & Probability & 0.000220 \\
\hline
\end{tabular}




\section{MlMacrothink}

Business and Economic Research ISSN 2162-4860 2013, Vol. 3, No. 2

Significant coefficients in term t-statistic and probability are considered. The lag order chosen for the estimation of our model is equal to 1. This order is selected, while setting a range of maximum delay and estimates the model parameters using the method of ordinary least squares.

The $\beta$ coefficient has a positive and significant value since the t-statistic is equal to $3.701321>1.96$ for a significance level of 5\%, which asserts the dependence of trading volume market performance in the previous period. The significance of the coefficient $\mathrm{C}$ is of the order (0.000483) may also assert that relationship.

The next step is to estimate the conditional expectation, that is to say, to calculate the conditional mean return series to select the orders of AR and MA parts from correlograms coefficients series (for Both kinds of simple and partial autocorrelation).

This step is followed by a validation process using a test on the estimated coefficients (which must be significantly different from zero), and another on residues that informs us about the fact that the estimated residuals follow a process white noise (absence of auto-correlation). The choice of the most appropriate model is based also on the criteria of information that tends to minimize AIC, SC and HQ criteria and maximize the log-likelihood slight improvement, since this value reflects a further refinement of the model.

a) Test on the coefficients:

the analysis of these correlograms allows the identification of order $p=1$, and an order $q=2$, this result provides three processes (AR ( 1), MA (2) and ARMA (1,2)), the next step is to perform a test on the coefficients by parameter estimation, due to this estimate, two processes namely AR (1) and MA (2), are candidates for applying the following test, when the process $\operatorname{ARMA}(1,2)$ is rejected as non has a significance level of one of these coefficients.

The estimation results of three $\operatorname{AR}(1), \operatorname{MA}(2)$ and $\operatorname{ARMA}(1,2)$.

Table 9. Estimation Results of AR (1)

\begin{tabular}{|l|l|l|l|}
\hline statistics & coefficient & t-statistics & Probability \\
\hline C & 0.000639 & 4.620501 & 0.0000 \\
\hline AR (1) & 0.217221 & 10.47350 & 0.0000 \\
\hline AIC & -7.719279 & & \\
\hline SC & -7.714133 & & \\
\hline HQ & -7.717399 & & \\
\hline LM & 8558.821 & & \\
\hline
\end{tabular}

Particularly, the constant $C$ is significantly different from zero (4.620501> 1.96) similarly for the coefficient AR (1) such that (10.47350>1.96). This model is a candidate for the application of tests on the residue of this process. 
Table 10. Estimation results of MA (2)

\begin{tabular}{|l|l|l|l|}
\hline statistics & coefficient & t-statistics & Probability \\
\hline C & 0.000643 & 4.543234 & 0.0000 \\
\hline MA (1) & 0.207374 & 9.809473 & 0.0000 \\
\hline MA (2) & 0.102048 & 4.827188 & 0.0000 \\
\hline AIC & -7.722277 & & \\
\hline SC & -7.714561 & & \\
\hline HQ & -7.719459 & & \\
\hline LM & 8567.005 & & \\
\hline
\end{tabular}

This model is also to keep because of the significance of the coefficients. Specifically the three coefficients are significantly different from zero and then they check the t-statistics greater than 1.96, it is candidate for the verification of other tests.

Table 11. Estimation results for $\operatorname{ARMA}(1,2)$

\begin{tabular}{|l|l|l|l|}
\hline statistics & coefficient & t-statistics & Probability \\
\hline C & 0.000639 & 4.426216 & 0.0000 \\
\hline AR (1) & 0.209915 & 1.057080 & 0.2906 \\
\hline MA (1) & -0.004132 & -0.0020812 & 0.9834 \\
\hline MA (2) & 0.058827 & 1.281476 & 0.2002 \\
\hline AIC & -7.721229 & & \\
\hline SC & -7.710938 & & \\
\hline HQ & -7.717470 & & \\
\hline LM & 8562.983 & & \\
\hline
\end{tabular}

In contrast to the two processes previously estimated, the $\operatorname{ARMA}(1,2)$ has a non-significance level of coefficients, this appeared in coefficient of the MA (1) that negative one hand. On the other hand it gives off a t-statistic less than $1.96(-0.0020812)$.

This process is therefore, to reject the point of no significance and the negativity of one of these coefficients. This leads us to consider only two processes for the following tests, the AR (1) and MA (2).

b) Tests on the residuals:

*Autocorrelation test:

After removal of the ARMA $(1,2)$ model, we proceed to consider the autocorrelation of errors of the above process from their simple and partial patterns. For this, we uses has the Box-Pierce is based on two hypotheses: $\mathrm{H} 0: \rho_{1}=\rho_{2}=\ldots \rho \mathrm{k}=$

H1: there is at least one significantly different from zero $\mathrm{i}$

To perform this test, called the Q statistic is given by:

$$
Q=n \sum_{k=1}^{k} \rho
$$


With n: number of observations and $\rho_{\mathrm{k}}^{2}$ : coefficient of order $\mathrm{k}$ of the estimated residuals.

The verification of the autocorrelation is a comparison of the $Q$ statistic to the value displayed on the table $\chi^{2}(\mathrm{k})$. Therefore it retains $\mathrm{H} 0$ (no self-correlation) if and only if this statistic is less than the value of $\chi^{2}$ a likelihood for fixed risk.

Selected processes will be validated by another test or test on residuals autocorrelation of errors of two AR (1) and MA (2), following the analysis of correlograms of these two processes, the AR (1) is not a good model because it presents at two types of auto correlation, not significant (probability less than (0.05)) hence the rejection of the null hypothesis in favor of the presence autocorrelation, while for MA (2), the above probability (0.05) from which the acceptance of the null hypothesis (no autocorrelation).

c) Heteroscedasticity test:

The detection of heteroscedasticity of residuals is an essential step in determining the most appropriate model to study the relationship between the volume of transaction to overconfidence and excessive volatility.

There are a multitude of tests for heteroscedasticity, such as, Goldfold and Quandt test white of Haravey and ARCH test, which has been frequently used in the treatment of financial time series. This test is to perform an autoregressive regression of squared residuals on q delays

$$
e_{t}^{2}=\alpha_{0}+\sum_{i=1}^{q} \alpha i e^{2}{ }_{t-i}
$$

With:

$e_{t}$ : Refers to residues from the ARMA $(\mathrm{p}, \mathrm{q})$, the assumptions of this test are as follows:

$\mathrm{H} 0$ : homoscedasticity $=1$ and $\mathrm{q}=0$

H1: there is at least one significantly different from zero coefficients.

To conduct this test, the test statistic TR ${ }^{2}$ is used with $\mathrm{T}$ denotes the number of observations of the residual series and $\mathrm{R}^{2}$ is the coefficient of determination of autoregressive regression.

Under H0 the statistic $\mathrm{TR}^{2 \sim}$ the law $\chi^{2}$ (q). Especially if $\mathrm{TR}^{2}<\square^{2}$ (q), we accept the homoscedasticity hypothesis (H0).

The last test is a test of heteroscedasticity (test $\mathrm{ARCH}$ ) which is to study the heteroscedastic conditional variance observed from the correlogram of squared residuals from the MA (2). The results show that the probabilities are lower (0.05) where the rejection of the null hypothesis of homoscedasticity which confirms the existence of ARCH effect.

The ARCH test performed on our series residual gives us the following results: 


\section{$\triangle$ Macrothink}

Table 12. ARCH -LM test

\begin{tabular}{|l|l|l|l|}
\hline F-statistic & 449.5125 & Prob. F(1,2215) & 0.0000 \\
\hline Obs*R-squared & 374.0156 & Prob. Chi-Square(1) & 0.0000 \\
\hline
\end{tabular}

We notice from the results found that the probability associated with the statistic TR 2 is equal to 0.0000 , which is strictly less than 0.05 . Over all t-statistics are greater than 1.96 which confirms the existence of ARCH effect. There by verifying the heteroscedasticity of residuals MA (2).

The next step is to estimate the E-GARCH model that presents our third relationship. In this context, there are more than a candidate model to form the volatility, we chose MA (2)-EGARCH $(3,3)$ that minimizes the information criteria and maximizes the log likelihood.

Table 13. Criteria for choosing the optimal lag order (MA-EGARCH) (p, q)

\begin{tabular}{|l|l|l|l|l|}
\hline criteria & AIC & SC & HQ & LM \\
\hline MA(2)-EGARCH $(1,1)$ & -8.029431 & -8.011428 & -8.022855 & 8911.639 \\
\hline MA(2)-EGARCH $(1,2)$ & -8.028754 & -8.008179 & -8.021239 & 8911.888 \\
\hline MA(2)-EGARCH $(1,3)$ & -8.027870 & -8.004723 & -8.019415 & 8911.907 \\
\hline MA(2)-EGARCH(2,1) & -8.028531 & -8.007956 & -8.021016 & 8911.641 \\
\hline MA(2)-EGARCH(2,2) & -8.029711 & -8.006564 & -8.021256 & 8913.949 \\
\hline MA(2)-EGARCH(2,3) & -8.029179 & -8.003460 & -8.019785 & 8914.359 \\
\hline MA(2)-EGARCH(3,1) & -8.027731 & -8.004585 & -8.019277 & 8911.754 \\
\hline MA(2)-EGARCH(3,2) & -8.028951 & -8.003233 & -8.019557 & 8914.107 \\
\hline MA(2)-EGARCH(3,3) & $\mathbf{- 8 . 0 3 8 9 0 3}$ & $\mathbf{- 8 . 0 1 0 6 1 3}$ & $\mathbf{- 8 . 0 2 8 5 7 0}$ & $\mathbf{8 9 2 6 . 1 4 4}$ \\
\hline
\end{tabular}

The last step is to introduce the two components extracted from the estimated turnover based Rmt. These two f3 and f4 are components which respectively reflect the effect of the component related to the excess of confidence and independent of the overconfidence. F3 which is of the order $(0.977556)$ is greater than that F4 is the order $(0.089576)$ where the positive effect of the bias of overconfidence on the volatility of returns which confirms our third hypothesis.

Table 14. Results from the introduction of overconfidence:

\begin{tabular}{|l|l|l|l|}
\hline coefficient & Statistics & Std-error & Z-statistic \\
\hline W & -0.543801 & 0.293611 & -1.852112 \\
\hline F1 & 0.618981 & 0.468294 & 1.321778 \\
\hline F2 & 0.753497 & 0.124786 & 6.037762 \\
\hline F3 & 0.977556 & 0.380914 & 2.015036 \\
\hline F4 & 0.089576 & 0.054050 & 1.657258 \\
\hline K & 0.019701 & 0.053554 & 0.367868 \\
\hline
\end{tabular}




\section{Conclusions}

The purpose of this article was to shed light on the phenomenon of overconfidence observed in financial markets. Our research work was divided into three sections.

The first section has sought to present the main foundations of the theory of efficient financial markets as developed by the traditional theory based on the fact that people operate in the financial markets have rational behavior and prices at all times reflect all available information.

For this, several limitations have come to question this theory and have concluded that the inability of the traditional theory to reveal any anomalies in the financial market, we then oriented to the study of a new approach "finance behavior "that has developed from work in cognitive psychology that proposes to integrate not perfectly rational behavior in decision-making by investors.

The main promoters of this current Kahneman and Tversky (1979) who questioned the rational behavior of agents in favor of a psychological behavior by focusing on the relationship between psychology and finance, involving the psychology of investor in making its financial decision.

The idea comes from the presence of several biases that affect the rationality of investors and produce several anomalies such as excessive trading volume and excess volatility, we find among these biases through overconfidence, which is considered as an explanation important for several anomalies in financial markets.

This bias has formed a subject of several studies of economic and financial cost of its importance in decision-making of investors; this bias is defined as the overstatement of earnings and consolidated under estimate its error. The second section was devoted to the presentation of data collected from the stock market of Tunis, and the methodology (models, variables).

The last section provides our empirical investigation that focused on the study of the impact of overconfidence on investors' decisions on three assumptions, through the examination of a part of the relationship between trading volume and performance track to evaluate the responses asymmetry caused by striking information (private-public), on the other hand, the relationship between transaction volume and performance of the market through overconfidence and its role in generating the volatility of the Tunisian financial market.

In the analysis of the hypothesis of overconfidence we are interested in 27 Tunisian companies over the period January 2002 to December 2010 by a preliminary statistical analysis of time series of returns, turnover and the deviation of the market.

We proceed by studying the first hypothesis using the vector autoregressive model and impulse response functions, allowed us to identify that investors over-react on confidence after the shock of private information and under- react after the shock of Public Information. In the second case, the Granger causality test, allowed us to identify the performance gains market lead investors to negotiate over-confident in a more aggressive in previous periods 
this test shows a retroactive reaction in both directions.

The last assumption states that the volume of transactions of intensive investors and the increased confidence on the conditional volatility of the securities through the use of MA-EGARCH model seems most appropriate to explain this phenomenon.

Within this framework through overconfidence reflects the excessive volatility of conditional market return given the significance and importance of the coefficient and component related to this bias. This result allowed us to verify the third hypothesis. The obtained results indicate the importance of bias on confidence in the analysis of the specificities of the Tunisian financial market.

At the end, we believe that this work has some limitations, in effect, using daily data, for example, carries the effects of day of the week where the importance of considering other frequencies such as weekly that might give more meaningful results.

\section{References}

-Allais.M. (1953), "The behavior of rational man in front of the critical risk assumptions and axioms of the American school”, Economica, 21, Pages 7-27.

-Barber Brab, and Terrance Odean. (2001), "Boys will be boys: gender, over confidence, and common stock investment”, Quarterly Journal of Economics, 116, Pages 261-292.

-Bénabou Roland and Tirole Jean (2004), "Will power and Personal Rules" Journal of Political Economy, 112(4), Pages 848-886.

-Box G. E, and Jenkins G. M (1976), “Times Series Analysis: Forecasting control, Holden Day", San Francisco, p575.

-Broihanne.M-H, Merli. M and Roger. P. (2004), "Behavioral portfolio theory: advantages and limitations", Pages 297-314.

-Chuang,Wen-I and Lee Bong-Soo (2006), “An empirical evaluation of over confidence hypothesis", Journal of Banking et finance, 30(9), Pages 2489-2515.

-Daniel Kahneman and Amos Tversky. (1979), "Prospect Theory: An Analysis of Decision Making under Risk” Econometrica, 47, Pages 263-294.

-Daniel, Kent, Hirshleifer, David, and Teoh, SiewHong (2002), "Investor psychology in capital markets: evidence and policy implications", Journal of Monetary Economics, 49, Pages 139-209.

-De Bondt. W., and R. H. Thaler, (1995), "Financial decision-making in markets and firms: a behavioral perspective", in (R. A. Jarrow, V. Maksimovic and W. T. Ziemba, eds), Finance, Handbooks in Operations Research and Management Science, Amsterdam: North Holland 9, Pages 385-410.

-Dimitris Andriosopoulos a, Kostas Andriosopoulos b, and Hafiz Hoque (2013), "Information disclosure, CEO overconfidence, and share buyback completion rates", Journal of Banking \& 
Finance (2013).

-Fama. E. (1965), “The behavior of stock market prices", Journal of business, 38(1), Pages 31-105.

-Fama. E. (1991), “efficient capital market: II” Journal of Finance, 46(5), Pages 1575-1617.

-Gerlinde Fellner, and Sebastian Krügel. (2011), "Judgmental overconfidence: Three measures, one bias?” Journal of Economic Psychology, 33(2012), Pages142-154.

-Herbert Simon. (1978); "Rationality as Process and as Product of throught", Americain Economic Review, 68, Pages 1-16.

-Kumar Alok (2006), "When do investors exhibit stronger behavioral biases?” working paper, university of Notre dame.

-Lovigne and Legros (2005), "behavioral finance and pension funds", Research Paper No 2005.31, Laboratory of Economics Orléan, octobre2005.

-Lukas Menkhoffa, Maik Schmelinga, and Ulrich Schmidtb,c,(2013), "Overconfidence, experience, and professionalism: An experimental study", Journal of Economic Behavior \& Organization, 86(2013), Pages 92-101.

-Markus Glaser and Martin Weber. (2004), “over confidence and trading volume”, working paper, University of Mannheim.

-Odean Terrance (1998), “Are Investors Reclutant to realize their losses?” Journal of Finance, 53(5), Pages 1775-1798.

-Rabin.Matthow and Richard Thaler (2004), "Anomalies: Risk Aversion", Journal of Economic Prespectives, 15(1), Pages 219-232.

-Ronald Huisman, Nico L. van der Sar, and Remco C. J. Zwinkels (2012), "A new measurement method of investor overconfidence", Economics Letters, 114(1), 69-71.

-Ross. S. A. (1976), "the arbitrage theory of capital asset pricing", Journal of Economic Theory, 13, Pages 341-360.

-Sanjay Deshmukh a, Anand M. Goel b, and Keith M. Howe a, (2013), "CEO overconfidence and dividend policy” J.Finance. Intermediation, 22(2013), Pages 440-463.

-Shiller, Robert J. (1997), "Human Behavior and the Efficiency of the Financial System", in John Taylor and Michael Woodford, eds., Handbook of Macroeconomics, 1C, 1305-40, Amsterdam: Elsevier, 1999.

-Statman. M, Thorly.S and Vorkink (2004), "Investor over confidence and trading volume". Review of Financial Studies, 19(4), Pages 1531-1565.

-Stracca.Livio. (2004), “Behavioral Finance and asset Prices: where dowestand?" Journal of Economic Psychology, 25, Pages 373-407.

-Walliser.B (1989), “Instrument cognitive Rationality Theory and Decision”, 27(1-2), Pages 
7-36.

\section{Copyright Disclaimer}

Copyright reserved by the author(s).

This article is an open-access article distributed under the terms and conditions of the Creative Commons Attribution license (http://creativecommons.org/licenses/by/3.0/). 